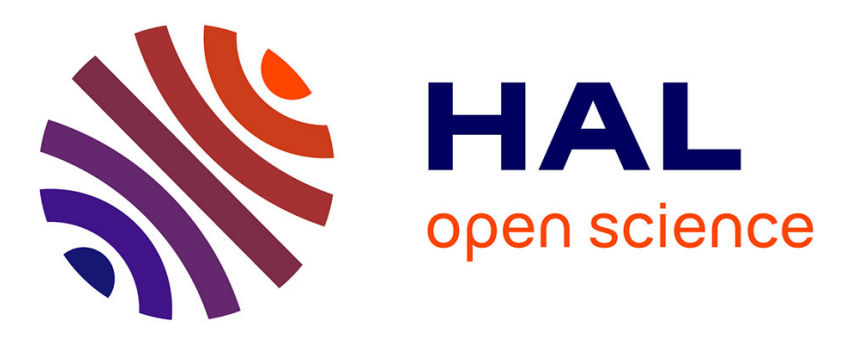

\title{
Contribution to Silicon-Carbide-MESFET ESD robustness analysis
}

\author{
Tanguy Phulpin, Karine Isoird, David Trémouilles, Patrick Austin, X. \\ Perpinya, J. Leon, M. Vellvehi
}

\section{- To cite this version:}

Tanguy Phulpin, Karine Isoird, David Trémouilles, Patrick Austin, X. Perpinya, et al.. Contribution to Silicon-Carbide-MESFET ESD robustness analysis. IEEE Transactions on Device and Materials Reliability, 2018, 18 (2), pp.214-223. 10.1109/TDMR.2018.2817255 . hal-01740513

\section{HAL Id: hal-01740513 https://hal.science/hal-01740513}

Submitted on 22 Mar 2018

HAL is a multi-disciplinary open access archive for the deposit and dissemination of scientific research documents, whether they are published or not. The documents may come from teaching and research institutions in France or abroad, or from public or private research centers.
L'archive ouverte pluridisciplinaire HAL, est destinée au dépôt et à la diffusion de documents scientifiques de niveau recherche, publiés ou non, émanant des établissements d'enseignement et de recherche français ou étrangers, des laboratoires publics ou privés. 


\title{
Contribution to Silicon-Carbide-MESFET ESD robustness analysis
}

\author{
T. Phulpin, K. Isoird, D. Trémouilles, P. Austin, X. Perpinyà, J. León, M. Vellvehi
}

\begin{abstract}
In this work, ElectroStatic Discharge (ESD) tests are performed on SiC MESFETs in order to understand their physical behavior and failure mechanisms during such stresses. The purpose is to point out advantages and drawbacks of this technology, paying special attention to aspects related to its possible commercialization and reliability. Three MESFETs designed to be integrated as a driver in monlithic $\mathrm{SiC}$ systems, featuring some ESD internal protection are investigated. Different configurations on ohmic and Schottky contacts are analyzed. Lock-in thermography is carried out for the physical failure location. With TCAD Sentaurus simulation, it allows to determine the nature of the defects on the damaged areas. Hypothesis on the failure mechanism as $\mathrm{SiO}_{2}$ breakdown or $\mathrm{SiC}$ sublimation are presented. Solutions to increase the ESD robustness such as a Zener diode integration or the use of Al2O3 dielectric for passivation are therefore proposed in this article.
\end{abstract}

Index Terms - ESD, MESFET, Passivation, Protection, Reliability, Integration, SiC, Schottky contact, Schottky diode, TLP, Zener diode

\section{INTRODUCTION}

$\mathrm{R}$ ELIABILITY and robustness of power semiconductor devices are primordial in any final application. In this regard, ElectroStatic Discharge (ESD) robustness is one of the critical aspects. ESD induce destructive failures or aging in such devices, reducing their life time [1]. Thus, understanding the failure mechanisms during ESD events is crucial to improve robustness, especially in new emerging materials such as Silicon Carbide ( $\mathrm{SiC}$ ) [2]. $\mathrm{SiC}$ is a promising wide band gap material for manufacturing power semiconductor devices. It allows converters miniaturization and power losses reduction thanks to, among other physical properties, its high voltage breakdown and high operation temperature capability [3]. However, although $\mathrm{SiC}$ is pointed out as a good candidate for integrated systems working for example near motors, its behavior during ESD stresses is scarcely reported, analyzed, and explained in the literature. Only one work dealing in this subject was found [4]. The main difficulties to investigate in this field are due to high stresses produced by ESD tests, which suddenly breaks down the device.

This work was produced the 27/09/2016 at LAAS in Toulouse, Fr.

T. Phulpin works at GEEPS, (91192 Gif sur Yvette, FR); e-mail: tphulpin@centralesupelec.fr

D. Tremouilles, K. Isoird, P. Austin are at LAAS, (31400 TOULOUSE); email: dtrémoui@laas.fr, kisoird@laas.fr, austin@laas.fr

X. Perpinnyà and M. Vellvehi are at CNM Laboratory ((Barcelona, Spain); email: xavier.perpinya@imb-cnm.csic.es
This work intends to study under ESD tests, several SiC MESFETs specifically designed for integrated power systems working under harsh environment conditions.

This paper is organized as follows. First, the devices (based on ohmic and Schottky gates) and their ESD workbench are presented. Next, in Section III, the ESD results are discussed. In Section IV, a failure analysis using lock-in thermography, jointly with Technology Computer Aided-Design (TCAD) simulation, is carried out to determine their failure mechanism. Finally, in Section V, more rugged structures against ESD events are proposed.

\section{PRESENTAtion OF THE STUdiED DEVICES}

The following parts of the paper will present these devices and the test setup used for the evaluation of their ESD robustness.

\section{A. Three different topologies}

Because of the difficulty to obtain homogenous doping along $\mathrm{SiC}$ material [5], mesa configuration is often used to optimize the dopant repartition and the termination junction of $\mathrm{SiC}$ power devices. Mesa isolation also brings an efficient electrical isolation but planar device makes this integration easier. Circle isolation with a high $\mathrm{P}$ doping layer is then preferred.

The studied devices measure $80 \mu \mathrm{m}$ large and $160 \mu \mathrm{m}$ long and are made of $0.5 \mu \mathrm{m} \mathrm{N}$-channel doped at $10^{17} \mathrm{~cm}^{-3}$ with phosphorus over a $5 \mu \mathrm{m}$ P-layer doped at $5.10^{15} \mathrm{~cm}^{-3}$ with Boron. The $\mathrm{N}$ channel is circled with a $\mathrm{P}^{+}$layer at $10^{19} \mathrm{~cm}^{-3}$ for the lateral isolation, which provides with the P-layer a RESURF (REduced SURface Field effect [6]) for the electric field repartition. Phosphorus at $10^{17} \mathrm{~cm}^{-3}\left(\mathrm{~N}^{+}\right)$is added for increasing the source and drain contact. A second gate called body is in contact with the P-layer and can be used to increase transconductance of the device.

The three MESFETs are essentially identical but internal protection was added (Fig.1.). One MESFET is used as reference one (MR). The second has a Zener diode on the drain electrode (MZD) in order to derive an overcurrent through the body layer. On their layout, we can observe a body layer (in red) circling the transistor, with a $2 \mu \mathrm{m} \mathrm{N} \mathrm{N}^{+}-\mathrm{P}^{+}$ juxtaposition for MZD for building the Zener diode (Fig.2.). The third device has no Zener diode but is protected with a Schottky diode on the drain electrode (MSD), allowing the drain current only in one way. It requires more potential to be triggered on and avoids any problem of inversion polarization. 
A layout of a planar MESFET with its respective internal protection in Fig.3.

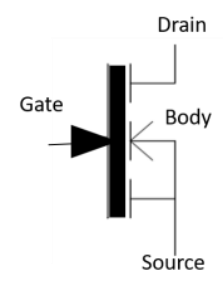

reference MESFET (MR)

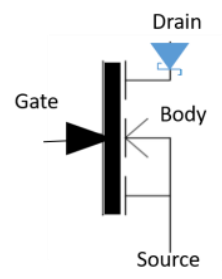

Schottky on drain MESFET (MSD)

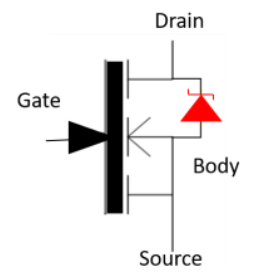

Zener on drain MESFET (MZD)
Fig.1. Planar MESFET with internal diodes protection

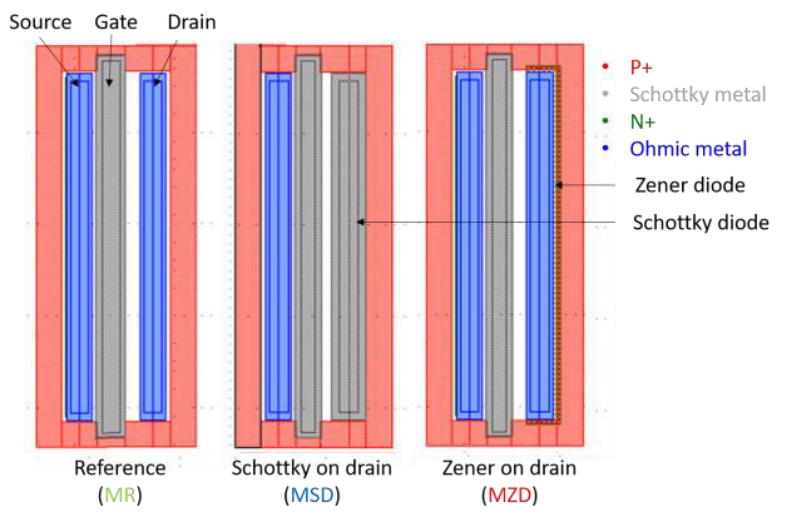

Fig.2. MR, MSD and MZD layout

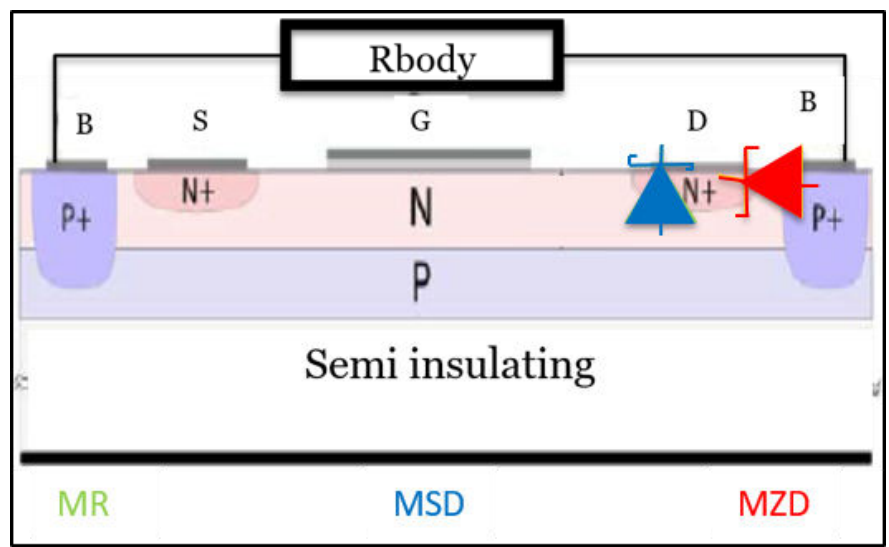

Fig.3. Schematic cross section of MR and MSD and MZD with their internal protection

Regarding device static measurement with $\mathrm{V}_{\mathrm{gs}}$ floatting, MSD presents a slight shift because of the diode conduction in comparison with the others devices, which have the same characteristics, depending on the different devices (Fig.4.). For the three signals, current saturation is around $16 \mathrm{~mA}$ for a range of $0-15 \mathrm{~V}$. The threshold voltage is calculated at $-15 \mathrm{~V}$ with this equation:

$$
\text { Vblocked }=\left(W^{\wedge} 2 * q * N d\right) /(2 * \varepsilon)=-15 \mathrm{~V}
$$

With $\mathrm{W}=0.5 \mu \mathrm{m}, \mathrm{q}=1.6 * 10^{-19} \mathrm{C}, \mathrm{Nd}=5.5 * 10^{16} \mathrm{~cm}^{-3}$ and $\varepsilon=9,66$

Devices were characterized with $\mathrm{J}_{\mathrm{ds} \_\max }=60.68 \mathrm{~mA} / \mathrm{mm}$, $\mathrm{J}_{\mathrm{d} \_\_ \text {leak }}=116 \mu \mathrm{A} / \mathrm{mm}$ and $\mathrm{J}_{\text {gs_leak }}=2,68 \mu \mathrm{A} / \mathrm{mm}[6]$.

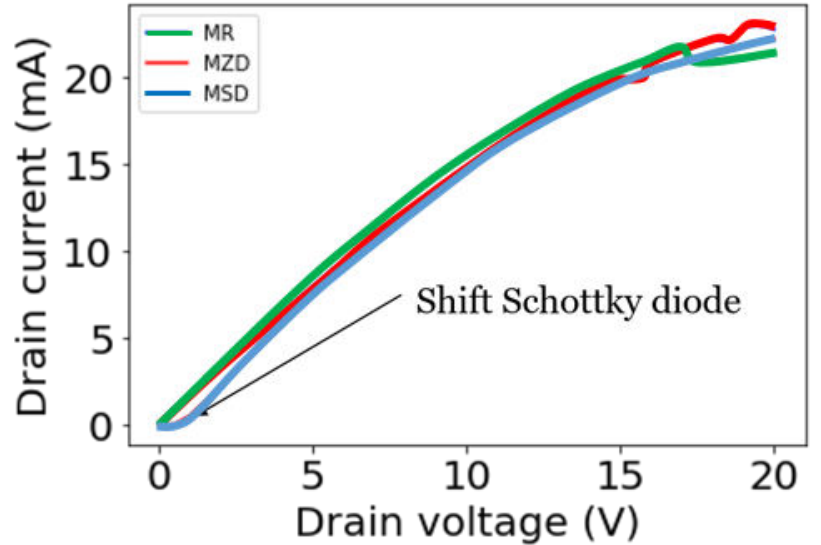

Fig.4. Ids-Vds characteristics for MR and MSD

Regarding device dynamic measurement, impedance is measured with AC signal of $0.5 \mathrm{~V}$ and DC signal of $0 \mathrm{~V}$. A phase around $90^{\circ}$ is observed at $10 \mathrm{MHz}$ with a maximum module value at $1 \mathrm{MHz}$. This figure indicates presence of passive element corresponding to a capacity, as it was demonstrated in [7]. Model used for the impedance measurement is therefore a capacitance in parallel with a resistance (Fig.5.) [8].

Drain-gate dynamic measurements $(1 \mathrm{kHz}-1 \mathrm{MHz})$ for MR and MZD are almost similar for internal capacitance (Fig.6.). 2 $\mathrm{k} \Omega$ are added by the Zener diode integration for resistance measurement. With frequency, $\mathrm{Cp}$ is constant whereas $\mathrm{Rp}$ increases due probably to the carrier saturation velocity. MSD is not plotted because its imaginary part is not comparable due the Schottky diode capacitance in serie with the drain-body measurement.

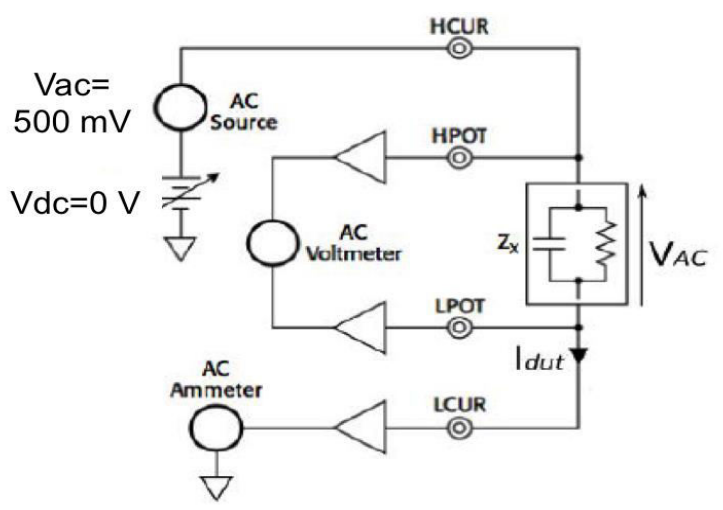

Fig.5. Schematic of the setup used for the impedance measurement [8] 

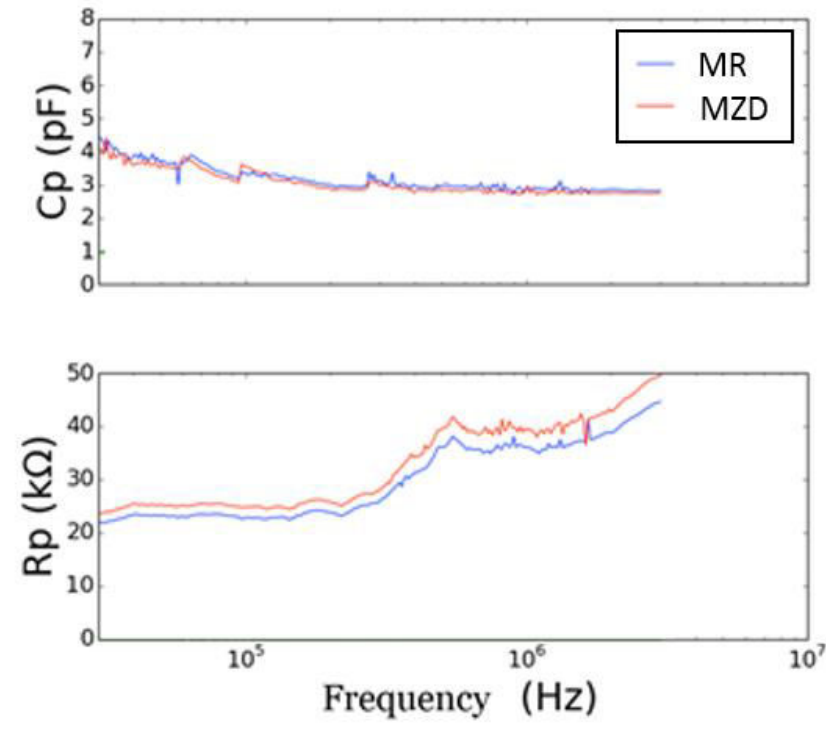

Fig.6. Impedance measurements on SiC MESFET MR, MSD, MZD

\section{B. TLP and HBM test}

Tests were realized with a Transmission Line Pulse (TLP) equipment setup to analyze the electrical behavior of the MESFET during ESD. HBM (Human Body Model) test is the standard test used for qualification in JEDEC ESD robustness. However, this test doesn't permit to study the electrical characteristics during experiments. TLP and HBM difference comes from the shape signal realized within a $100 \mathrm{~ns}$ step for TLP and a capacitor discharge for HBM. During experiments, stress amplitude is increased until electrical or physical failure. For TLP test, experiment is stopped as soon as failure Ids-Vds measurement, realized after each step, is modified by about $20 \%$ of the initial reference curve.

\section{MEASUREMENT AND RESULTS}

TLP stresses are realized at ambient temperature on each device and results are examined to understand the failure mechanism. First results are commented for a stress applied on the drain with the gate floating (ON state), then in OFF state condition. Eventually the stress is applied directly on the gate electrode for the Schottky contact ESD robustness comparison.

\section{A. Stress on drain (ON state)}

TLP stresses are applied on drain electrode with gate and body electrode floating. Results are displayed in the Fig.7. Each point corresponds to a stress level and stars indicate the destructive stress. In the contrary of silicon, reference measurement between each measure (here called leakage measurements) are not a failure indicator as seen in Fig.8. Indeed although devices are physically broken, only a small shift is observed. Visual indications have then to be used to stop the test as soon as a failure takes place.

TLP result shows similar behavior for MSD and MR with tens volt dispersion on voltage failure level, and with a failure at higher voltage value but very low current level. As the maximum drain current measured is around $20 \mathrm{~mA}$ for a voltage of $250 \mathrm{~V}$, the power sustain by these MESFETs is in both case around $5 \mathrm{~W}$.

In the contrary, MZD has still the same TLP characteristics, with a current increasing at $115 \mathrm{~V}$, until $1 \mathrm{~A}$ and $130 \mathrm{~V}$. The power sustain is then around $130 \mathrm{~W}$. In this case, the device conducts the ESD current and is not physically degraded.

Standard HBM test confirms a better MZD ESD robustness. Whereas MR and MSD have the same behavior with a failure observed visually at approximately $420 \mathrm{~V}$, MZD can withstand around $1250 \mathrm{~V}$ and $0.9 \mathrm{~A}$ even if his electrical characteristics are not modified. The JEDEC classification, which is the reference in ESD, is then different with class 1C for MZD instead of class 1A for MR and MSD [9]. This better ESD classification allows the main works in laboratory without specific protection with MZD. In addition after the HBM test, failure looks different for MZD because the current increase, signature of the failure in case of MR and MSD was not detected in HBM I-V measurement. However, a failure is physically observed and looks similar from the optical point of view with the same localization.

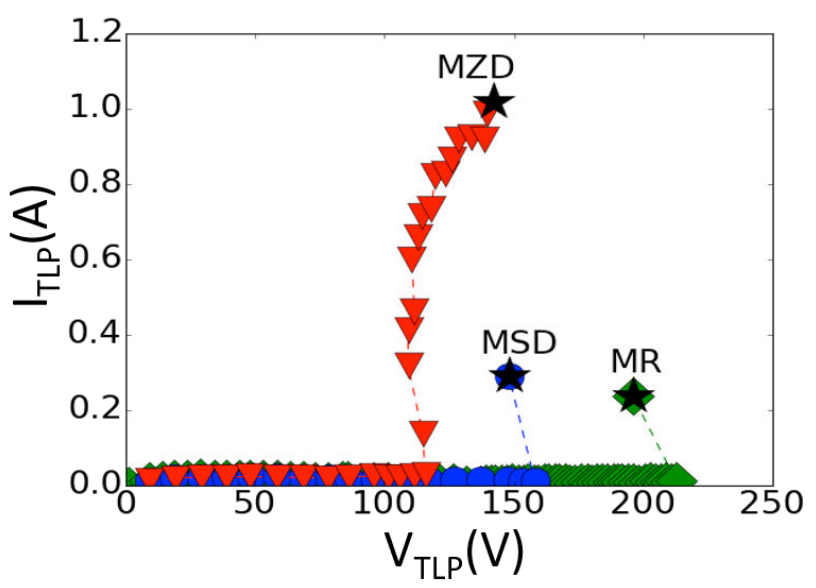

Fig.7. SiC MESFET TLP between drain and source with Vgs=0V. Stars are represented the failure point
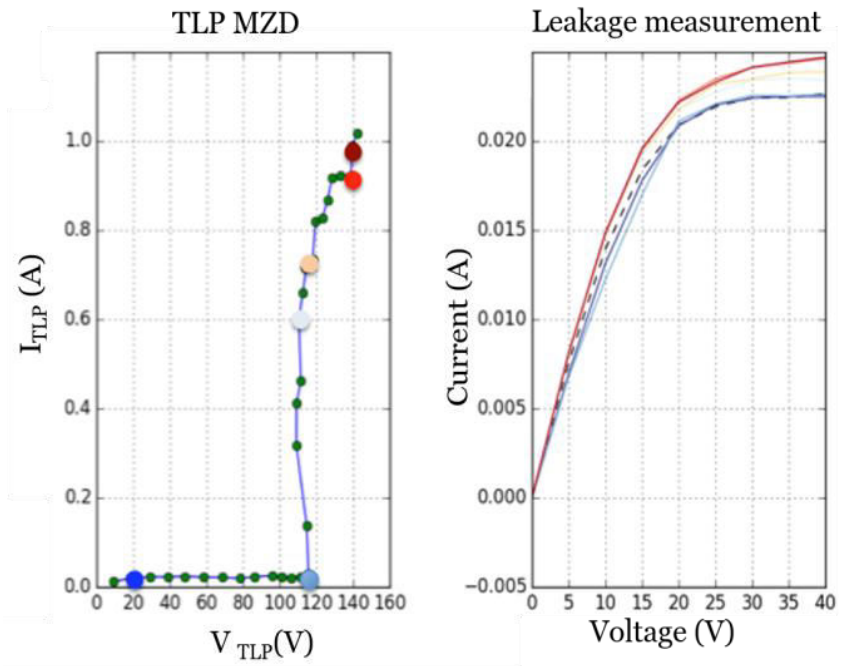

Fig.8. DC leakage curve during TLP experiment on SiC MZD 


\section{B. Stress on drain (OFF state)}

An external generator supplying $-15 \mathrm{~V}$ on gate electrode is added to our TLP benchmark. The measured off-state leakage is $0.004 \mathrm{~mA}$ in the gate biased condition of $-15 \mathrm{~V}$, indicating the device is blocked..

Results of the TLP test on the drain are reproducible and show three different behaviors (Fig.9.). MR and MSD present now a different electrical behavior with a different failure mechanism. Indeed, MR has a current increase before failure, and handles $0.4 \mathrm{~A}$ and $280 \mathrm{~V}$ before failure, which corresponds to $112 \mathrm{~W}$. MZD is broken at $0.5 \mathrm{~A}$ and $230 \mathrm{~V}$, for power almost similar than in the previous experiment and almost equal to MR failure power. However the current hasn't the same behavior in both cases with a different internal resistance evolution. Results and failure are similar than previously for MSD without any overcurrent.

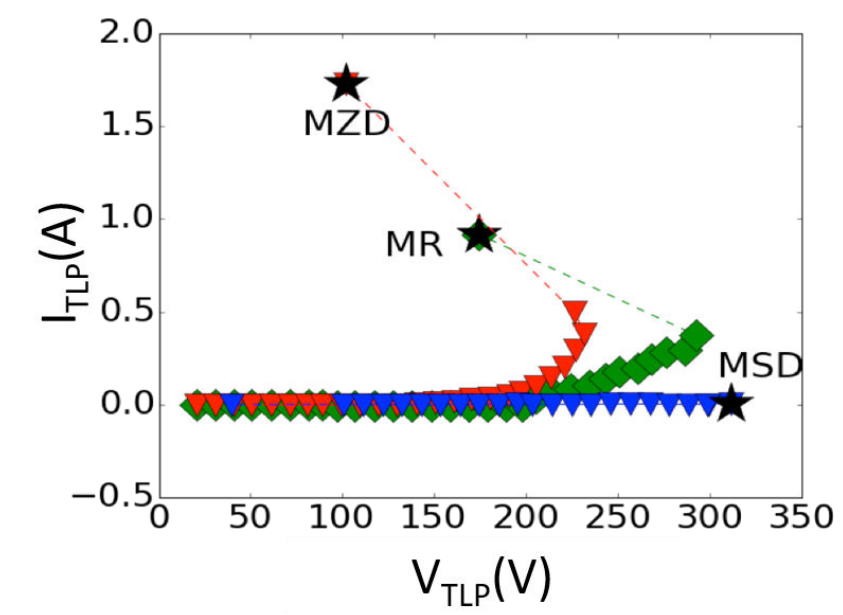

Fig.9. SiC MESFET TLP between drain and source, with Vgs=-15V and body floating. Stars are represented the failure point

\section{Stress on gate}

Stress is applied on Schottky contact between gate and source electrodes with the others terminals floating. TLP result presents a failure in direct mode at $100 \mathrm{~V}$ with $0.2 \mathrm{~A}(20 \mathrm{~W})$ and only $230 \mathrm{~V}$ with $0.02 \mathrm{~A}(5 \mathrm{~W})$ in reverse mode (Fig.10.). The TLPfailure power level is equal in reverse mode to MSD failure power level.

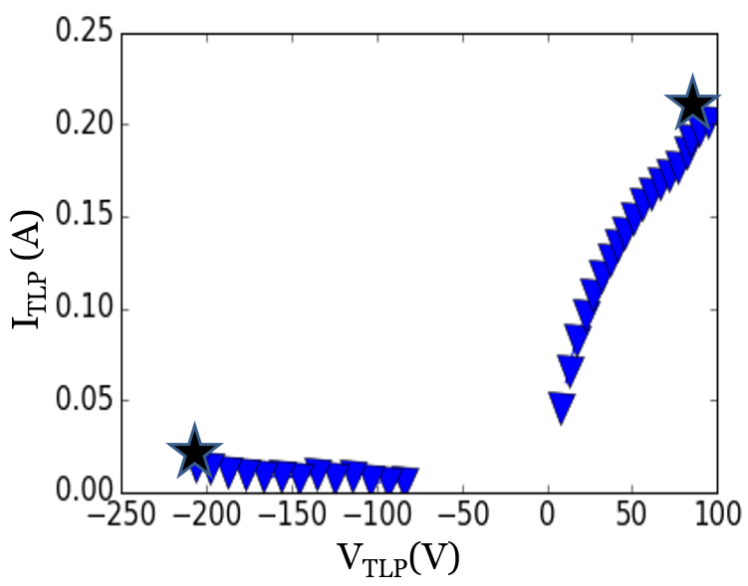

Fig.10. One negative and one positive TLP stress between gate and source electrode for SiC MESFET with drain foatting. Stars are represented the failure point

\section{Sum up of results}

The following table (Tab.1.) sum up the different result of TLP voltage and power sustain by the stressed device.

Tab.1. Results after TLP stress experiments on SiC MESFET

\begin{tabular}{|c|c|c|c|}
\hline Stress & MR & MSD & MZD \\
\hline Drain with & $\mathrm{V}_{\mathrm{br}}=200 \mathrm{~V}$ & $150 \mathrm{~V}$ & $115 \mathrm{~V}$ \\
$\mathrm{~V}_{\mathrm{gs}}=\mathrm{oV}$ & $\mathrm{P}_{\mathrm{br}}=5 \mathrm{~W}$ & $5 \mathrm{~W}$ & $115 \mathrm{~W}$ \\
\hline $\begin{array}{c}\text { Drain with } \mathrm{V}_{\mathrm{gs}}=- \\
280 \mathrm{~V}\end{array}$ & $310 \mathrm{~V}$ & $230 \mathrm{~V}$ \\
$15 \mathrm{~V}$ & $112 \mathrm{~W}$ & $5 \mathrm{~W}$ & $115 \mathrm{~W}$ \\
\hline $\begin{array}{c}\text { Gate with Drain } \\
\text { floatting }\end{array}$ & $100 \mathrm{~V}$ & - & - \\
\hline
\end{tabular}

\section{FAILURE ANALYSIS}

In a first part, Lock-in thermography is used as failure detector. It allows in our case to separate in two groups origin of the failures and it brings correlation between electrical and physical failure. Then for the failure analysis, microscopic observations are used and are compared to TCAD Sentaurus simulations. This analysis contributes to the failure mechanism understanding.

\section{A. Lock-in thermography}

Lock-in thermography (LIT) is a general approach capable of locating the physical failure after an ESD event, based on the frequency modulation of heat sources or hot spots, which correspond to faulty locations on the device surface. After an acquisition of the thermal field and following a data lock-in postprocessing strategies, thermal amplitude and phase lag at one frequency are measured [10] and such heat sources are detected. Concretely, lock-in thermography can be implemented with an Infrared (IR) camera, recording IR photon emission of the studied device with a high spatial resolution $(5 \mu \mathrm{m})$.

This work has been done at CNM laboratory. Samples have been biased with a sine-like signal at a given frequency to carry out the lock-in detection. After data collection and mathematical convolution [9], amplitude and phases are analyzed at the biasing frequency. Only amplitude results are 
presented here, as they are of significance for the intended study: locate hot spots as indicators of physical failure positions. Scale of infrared emission is the same for all graphs, without legends because the value measured are related to the average of each measure

TLP stress creates a failure on MR (Fig..11.) but failures are not revealed by the LIT (Fig.12.): no modifications are observed before and after stress whereas a failure is visually observed with a microscope. We can observe on the figure that most of current is going uniformly through the gate electrode, which is lighter between the drain-source electrode. MSD has a similar behavior. However, for MZD, results are different as shown in Fig.13. and Fig.14. With the emission scale, we can just deduce that a failure occurs in $\mathrm{SiC}$ and where it is localized. The failure nature can not be easily interpreted but confirms the difference of mechanism with MR or MSD.

The colored LIT signal for MZD is concentrated at the failure localization. A hypothesis of the different LIT signal of MZD before and after the failure is that electric field is concentrated all around the defect as shown in Fig.15. In this simulation, we can observe an example in 2D, with two lateral NPN $10 \mu \mathrm{m}$-device polarized at $50 \mathrm{~V}$ : one with a hole, corresponding to the observed defect in $\mathrm{SiC}$ [12] and one without. Result of this simulation is that electric field, related to current distribution, is more concentrated around the hole and presents stronger values for the "hole" device than for the "normal" device. Hence it justifies the current increase in the DC leakage current measurement during the TLP test (Fig.7.).

The LIT analysis indicates probably the internal defect in case of MZD, and external defect in case of MR and MSD. This analyze justifies the LIT representation and the slight DC current leakage increased noticed after ESD stress for MZD. In any cases, the LIT allows detecting the defect creation on $\mathrm{SiC}$ and permits the localization of the failure even if the accuracy is limited by the camera's resolution $(5 \mu \mathrm{m})$.

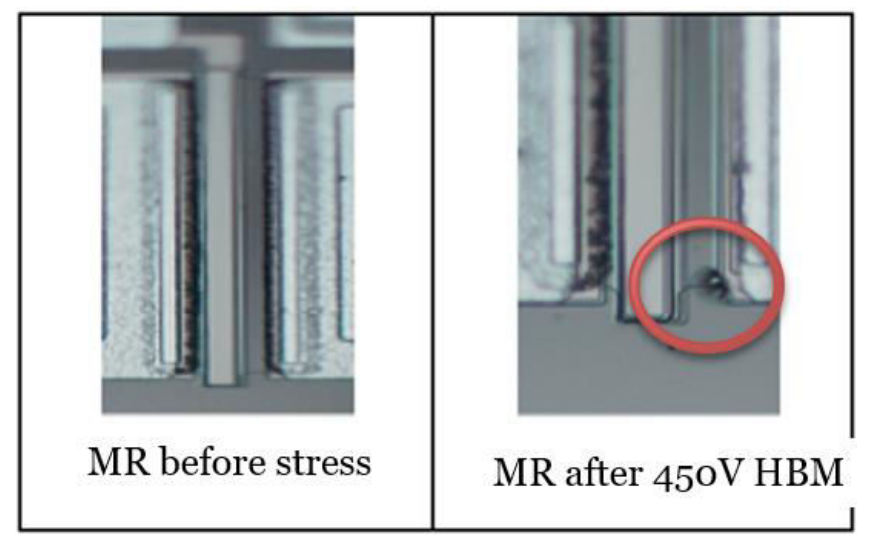

Fig.11. MR photography before and after destructive HBM stress on the drain with gate floatting

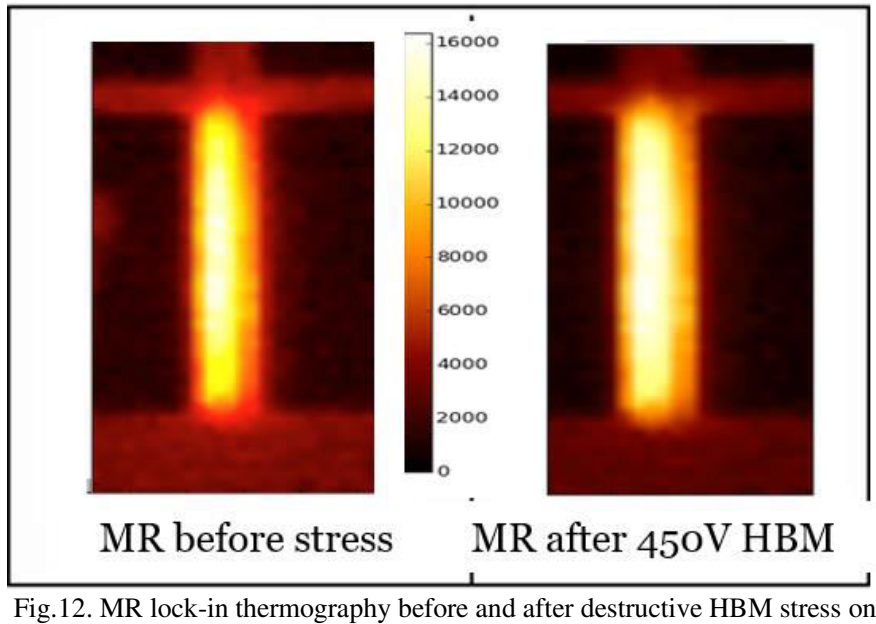

Fig.12. MR lock-in thermography before and after destructive HBM stress on the drain with gate floatting

\section{B. Visual observation}

1) Stress on drain

As described in previous works [12] [13], MR and MSD failure, in ON state condition, are related to the intermetallic dielectric breakdown, which is the weakest part of $\mathrm{SiC}$ technology [5] [14]. By contrast, when the N-channel is blocked, MR presents a different failure mechanism. Concerning MZD, failure looks to have the same origin even if the failure voltage level is different. Due to the Zener diode conduction, a parasitic transistor conducts current until failure. This transistor takes still place at the drain corner, at the body junction, where electric field is the highest. The Zener diode conduction in OFF state condition requires more voltage in comparison with ON state condition: this shift is induced by leakage current through the surficial layers, increasing the body potential as in Fig.16. In this figure, we can observe that electron current looks to find its origin with hole current coming from the gate. This current conduction may delay the parasitic transistor triggering (Fig.17.).

Furthermore, between MR and MZD, failure looks similar as shown in Fig.18. Even if electrical characteristics are different, TLP power failure is equivalent for MR and MZD and equivalent to MZD in ON state. Only current increase slope is different, meaning the internal resistance of the $\mathrm{I}_{\mathrm{TLP}} \mathrm{P}^{-}$ $\mathrm{V}_{\mathrm{TLP}}$ characteristic, measured here at around $\mathrm{R}_{\mathrm{MZD}}=75 \Omega$ and $\mathrm{R}_{\mathrm{MR}}=250 \Omega$. 


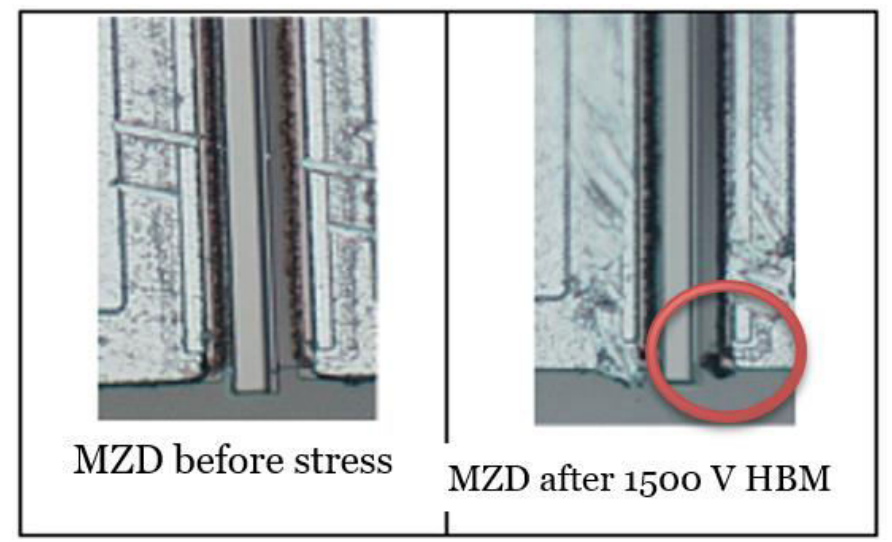

Fig.13. MZD photography before and after destructive HBM stress on the drain with gate floatting

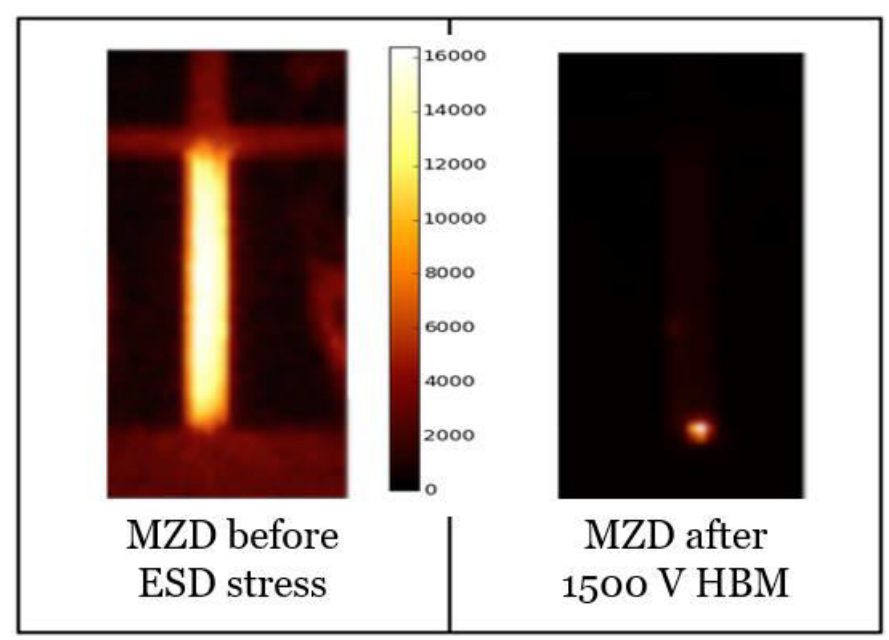

Fig.14. MZD lock-in thermography before and after destructive HBM stress on the drain with gate floatting

\section{2) Stress on gate}

Corresponding to MESFET's gate stress, results are similar for the three devices with positive stress, and with similar visual consequences (Fig.19.). The unmetallized part of the gate burnt.

In reverse biasing, failures are also reproducible and identical, with in addition the creation of a short between source and gate electrodes (Fig.20.). This short is localized now at the extremity of the gate metal.

In both cases, failures seem to correspond to the oxide breakdown. A short between gate and source is created and at around $200 \mathrm{~V}$, voltage is too high for the passivation layer composed of $\mathrm{SiO}_{2}$. Failure occurs for the same TLP power failure than MSD in Ohmic stress condition.

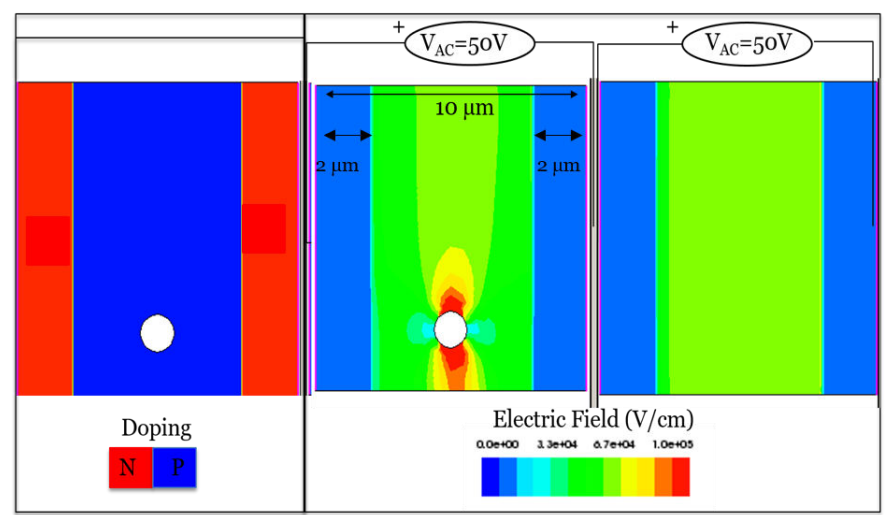

Fig.15. Example of TCAD simulation result with electric field repartition in two $\mathrm{SiC}$ lateral NPN, biased at $50 \mathrm{~V}$. One is presenting a defect, considered as a hole.

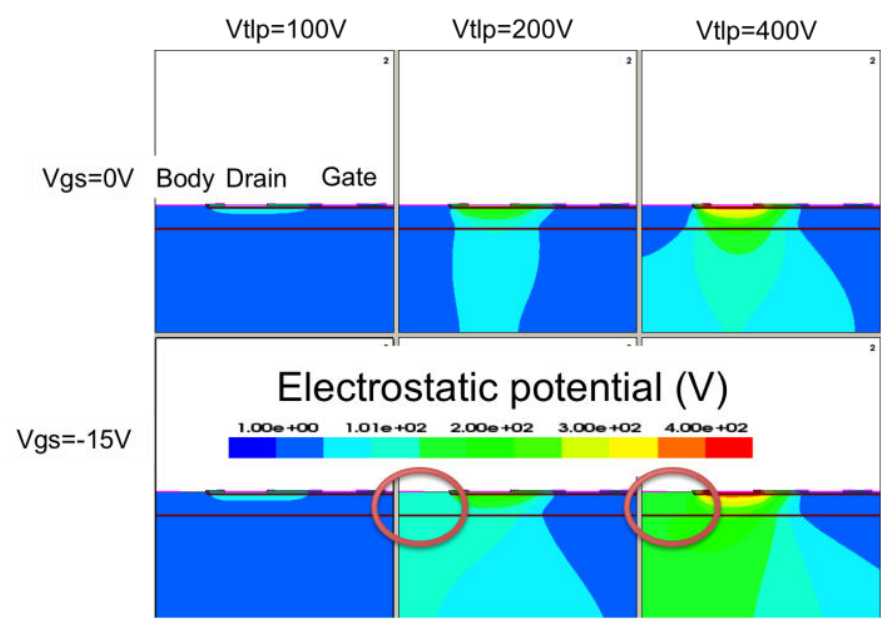

Fig.16. Simulation of the electric field repartition in blocked and unblocked MESFET

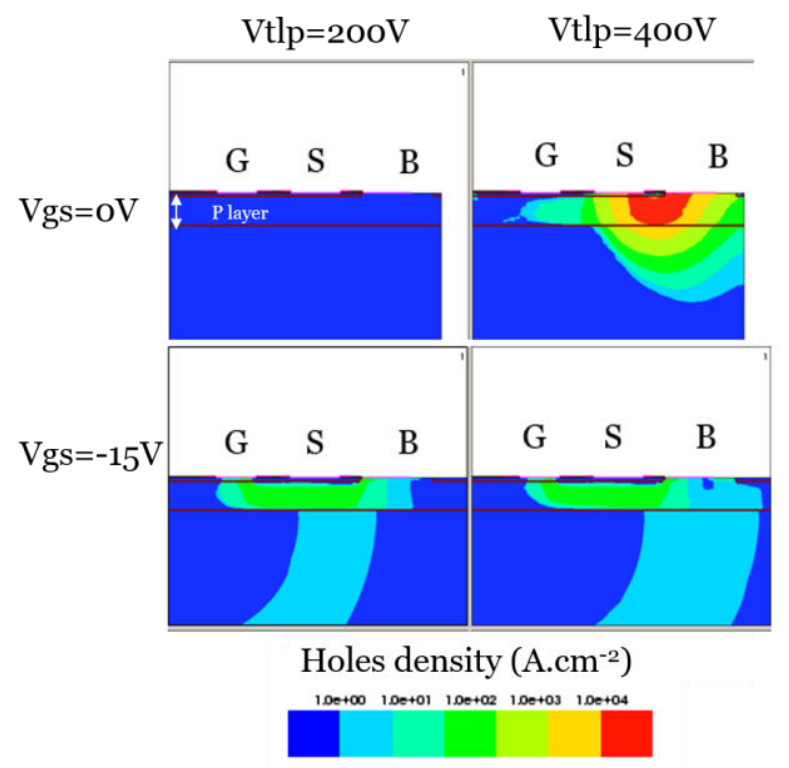

Fig.17. Simulation of holes density in ON and OFF state condition 


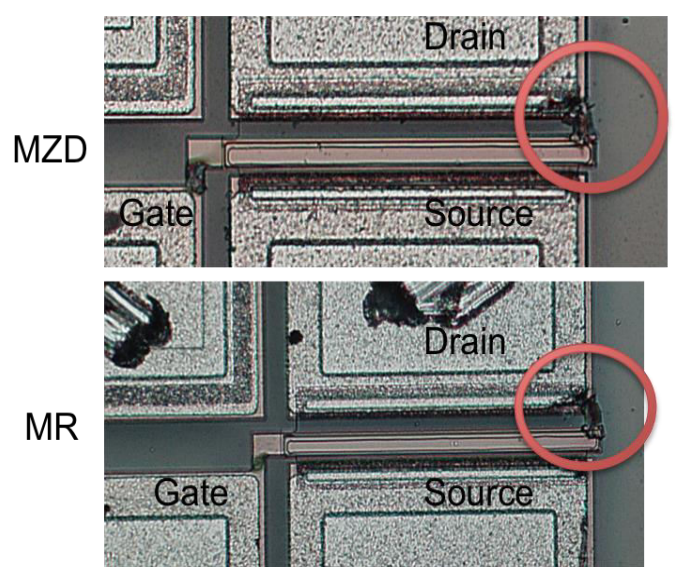

Fig.18. Failures on MR and MZD after TLP drain-source stress in Off state condition $\left(\mathrm{V}_{\mathrm{gs}}=-15 \mathrm{~V}\right)$

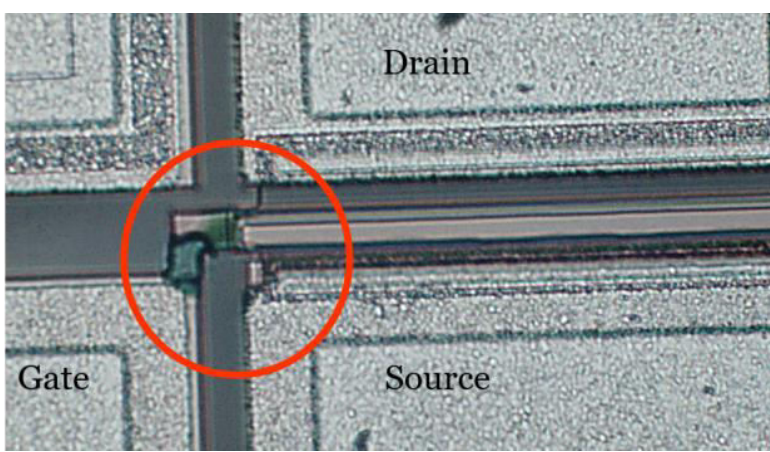

Fig.19. Failure on MZD after a positive TLP stress on the gate with drain electrode floatting

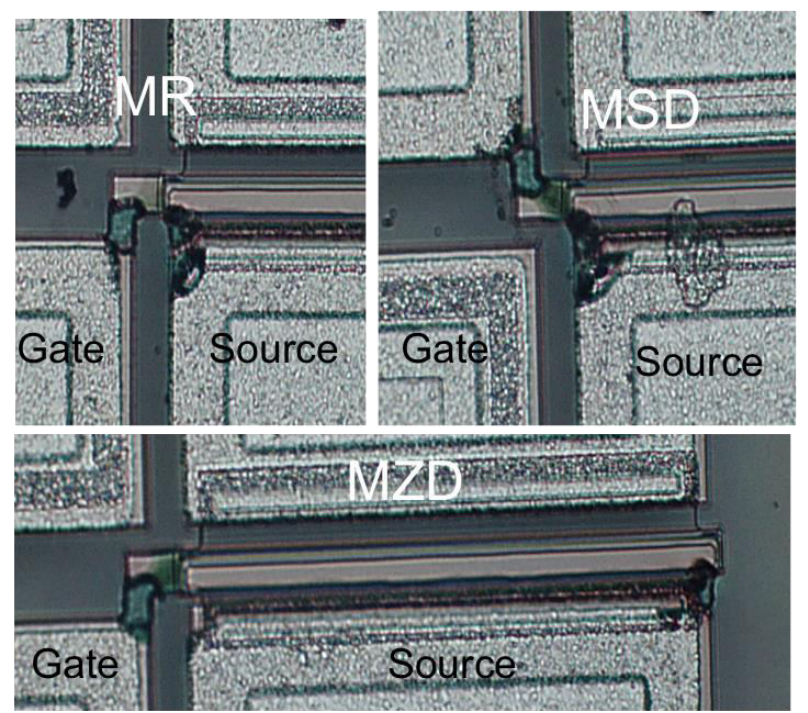

Fig.20. Failures on SiC MESFET provoked by negative TLP stress on the gate with drain electrode floatting

\section{DISCUSSIONS}

We try to understand the physical behavior during failure mechanism and what are the differences between each devices. Failures in ON state condition were already explained with a parasitic transistor triggering and with oxide breakdown [12] [13]. For the OFF state condition, hypothesis of the failure mechanism is here advanced. Finally the impedance measurement between broken and unbroken device will complete the study.

\section{A. Correlation with diode triggering}

As it was demonstrated, during TLP stress, internal diodes affect the device electrical behavior and trig on the failure mechanism. On our MESFETs, the only difference between MSD and MR, and MSD is the kind of diode or its localization.

For instance, MSD requires more voltage to inject carriers in the $\mathrm{N}$ channel than the other devices. MSD has indeed no $\mathrm{N}^{+}$area below the electrode privileging the drain-body diode conduction during high ESD stress. However failure occurs for high TLP voltage because oxide breakdown happens before current triggering,

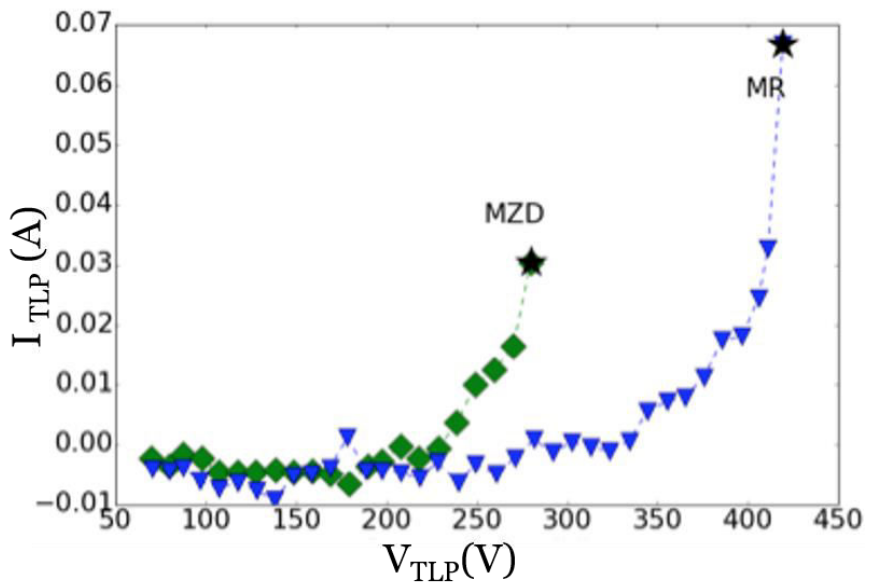

Fig.21. TLP between drain and body in MZD and MR: the diode triggering is different

For MR and MZD, the drain-body diode stressed in reverse mode indicates different TLP voltage value after current increase with different slope. Furthermore these values look higher than those of the entire MESFET failure ones (Fig.21.).

In this study, internal diode impact is, underline with MZD failure mechanism [13]. However, failure couldn't be due only to the Zener diode voltage triggering because the Zener diode is triggered at $30 \mathrm{~V}$ in static measurement. In TLP measurement, current increases after $85 \mathrm{~V}$ for MZD and after $115 \mathrm{~V}$ for the Zener diode even if failure is coming at around 250V. In blocked condition, the Zener diode TLP measurement indicates a small-triggering-current increase at around $250 \mathrm{~V}$ and a failure of the junction diode for $280 \mathrm{~V}$ is observed. As we can observe (Fig.22.), MZD failure is probably related to the Zener diode triggering but happens later in offstate configuration than in floating one.

The Zener diode triggering is responsible of the transistor triggering, which increases the drain-source current, hence the ESD robustness, until failure. The same phenomenon can also trig on the current increase with the P-N diode conduction and justifies the MR failure for the same power range.

Concerning the different slope, it corresponds to the difference of the internal resistance for each diode. With the parasitic transistor, the power become unsustainable for the device and a hole is created in the device as already demonstrated. 


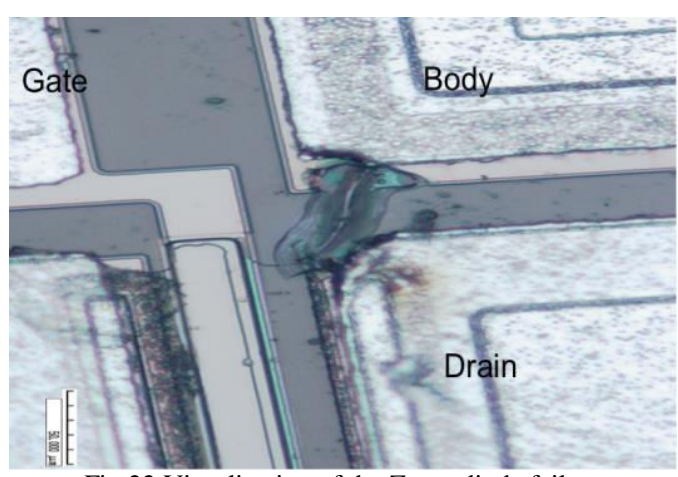

Fig.22.Visualization of the Zener diode failure

\section{B. Consequence of failure on impedance characteristic}

As we have seen, internal protections do not modify sufficiently the static and dynamic measurement even if they play a role by increasing the global ESD robustness of the MESFET.

Although passive values can be calculated, an adaptive circuit is required [15]. The purpose in this work is just to determine the internal impedance differences with broken devices for MR and MZD. The goal is to determine which part of the impedance is broken after destructive TLP stress.

Result in Fig.23. shows for broken MR a reduction and noise in the capacitance measurement and a reduced internal resistance, probably corresponding to internal capacity failure and the deterioration of the $\mathrm{SiC}$ surface. In the contrary for MZD, the capacity value increases with exactly the same signal form and the resistance measurement presents no modification. A buried hole is therefore created in the SiC.

Because of the parasitic NPN transistor, a local current increase produces a local heating in the $\mathrm{SiC}$ [12] resulting in $\mathrm{SiC}$ sublimation and the hole creation in the semi-conductor. This hole modifies the capacitance between drain and $\mathrm{P}^{+}$body and creates interferences in the dynamic measurements.
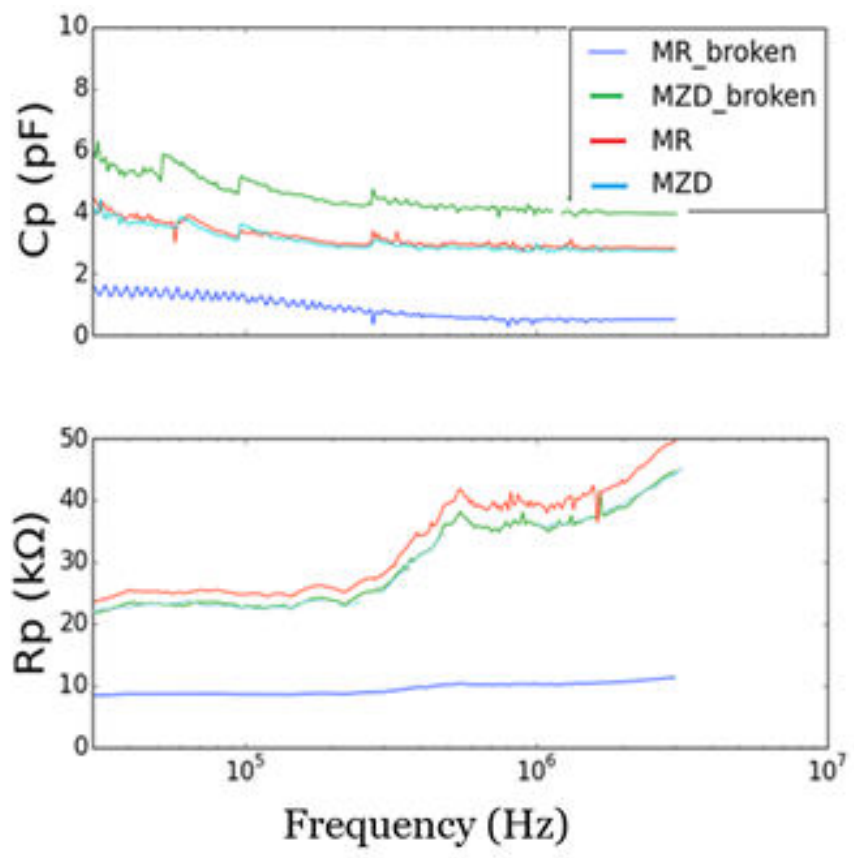

Fig.23. Dynamic measurements for MR and MZD on Drain-Body junction; Internal impedance has a failure

\section{ROBUSTNESS IMPROVEMENTS}

In order to increase the ESD robustness of the MESFET, a solution for canceling or delaying the different failures mechanism in regards with the avalanche voltage or with the passivation dielectric is presented.

\section{A. Body's metallization and Zener on drain improvement}

The MESFET structure is undoubtable a suitable configuration for the development of a parasitic transistor (Fig.24.). The ESD robustness of the design is limited because of this mechanism, triggered firstly by avalanche process as for MR and secondly with by the Zener triggering, hence injecting carriers below the source electrode as for MZD device.

Several possibilities for silicon devices exist for delaying this transistor, like alternative $\mathrm{N}^{+}$and $\mathrm{P}^{+}$area below the drain electrode [16] or like circular trench in the drain contact [17]. It globally permits to reduce the local current density below the electrode responsible of the parasitic transistor. Unfortunately, they were not tested or simulated in this work.

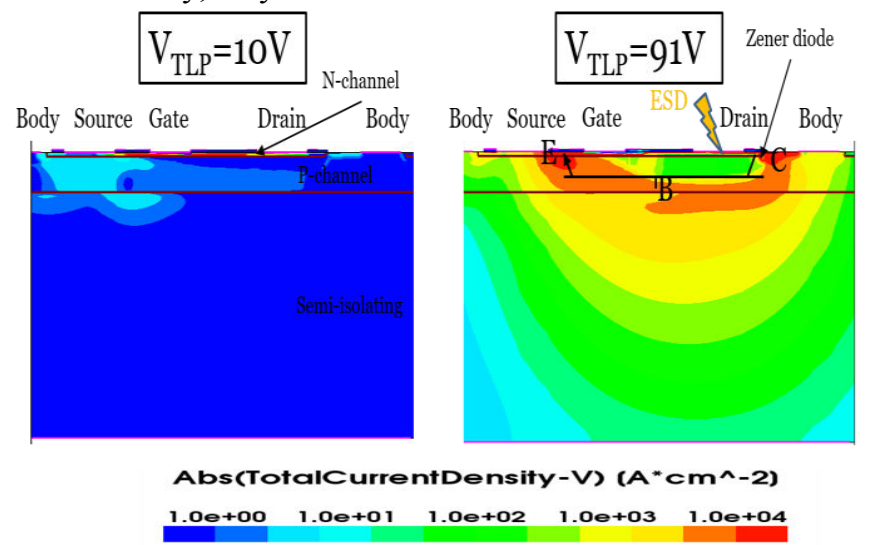

Fig.24. Current density representation on MZD layout before and after the parasitic NPN triggering 
Another way to delay the transistor triggering can be to add a metallization on the body layer in order to homogenize the internal resistance and hence spread the current repartition all over the surface of the device [13]. However this solution is not easy to put into practice because of the overlaying of several metals.

Eventually a solution could be to modify the channel thickness as it was demonstrated for a mesa-MESFET with a similar structure composition but it brings a tradeoff with our requirements as the voltage breakdown [12]. In Fig.25., the ESD robustness seems better with a P-channel of $1 \mu \mathrm{m}$ than with standard $0.5 \mu \mathrm{m}$ or $0.2 \mu \mathrm{m}$

In any case for delaying this premature NPN parasitic transistor triggering due to the avalanche voltage, the Zener diode linked to the body is still efficient, not disturbing the system and does not cost space, to the contrary of changing the passivation oxide.

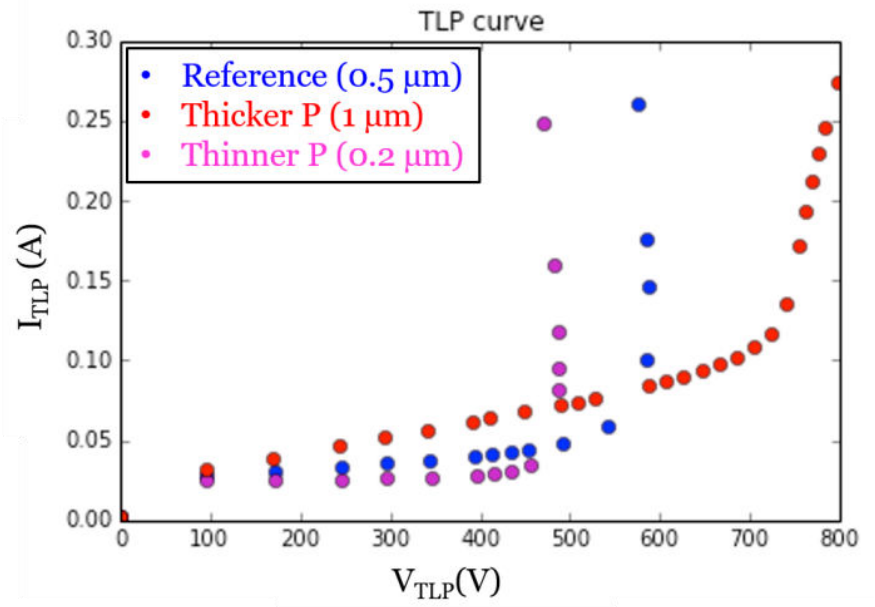

Fig.25. TCAD simulation of TLP test on mesa-MESFET with several P thickness

\section{B. Dielectric of passivation for SiC}

Thanks to TCAD Sentaurus package software, it has been possible to simulate breakdown field variation of the device with different dielectric layers (Tab.2). Simulations have been run just by changing the $\mathrm{SiO}_{2}$ by $\mathrm{HfO}_{2}$ or by $\mathrm{Al}_{2} \mathrm{O}_{3}$ which are dielectric, with a high dielectric constant, interesting for $\mathrm{SiC}$ [5] [13]. In this simulation, the dielectric thickness was also modified to match with the Atomic Layer Deposition (ALD) of these oxides, corresponding to the deposition method of these dielectric. A maximum thickness of $100 \mathrm{~nm}$ instead of $500 \mathrm{~nm}$ was selected. A breakdown criterion on the maximum electric field in the dielectric is added in the simulation.

Results for the aluminum oxide are interesting, with no oxide breakdown until $900 \mathrm{~V}$ whereas $\mathrm{HfO}_{2}$ and $\mathrm{SiO}_{2}$ simulation stop at their maximum electrical field criteria around 400V (Fig.26.).

We can also notice that the dielectric constant impact the current level (Fig.27.). Indeed the electric field in the passivation layer seems to saturate the N-channel. That's why high dielectric constant materials of passivation allow a higher current level.

Oxide breakdown is an important parameter to take into account for ESD robustness. Realization with $\mathrm{HfO}_{2}$ or $\mathrm{Al}_{2} \mathrm{O}_{3}$ is however limited by the time of deposition, which impact the deposition thickness limited to $100 \mathrm{~nm}$ due to the need of using ALD technique. It's hence not suitable for power devices which need thicker passivation layer. Other high-k materials have to be tested in order to find one suitable for $\mathrm{SiC}$ material.

\begin{tabular}{|c|c|c|}
\hline Materials & $\varepsilon_{\mathrm{R}}$ & Breakdown Field (MV/cm) \\
\hline $\mathrm{SiO}_{2}$ & 10 & 3 \\
\hline $\mathrm{HfO}_{2}$ & 20 & $5 \cdot 4$ \\
\hline $\mathrm{Al}_{2} \mathrm{O}_{3}$ & 9 & 12 \\
\hline
\end{tabular}

Tab.2. Table of simulated materials properties for SiC MESFET oxide passivation

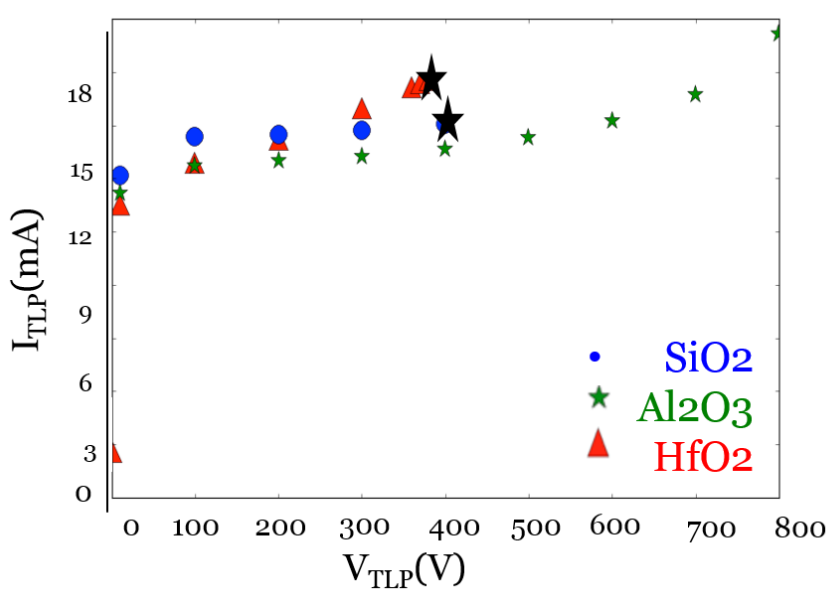

Fig.26. TLP test simulation on several passivation dielectrics MESFET. $\mathrm{Al}_{2} \mathrm{O}_{3}$ looks to be the most reliable because there is no oxide breakdown symbolize in black

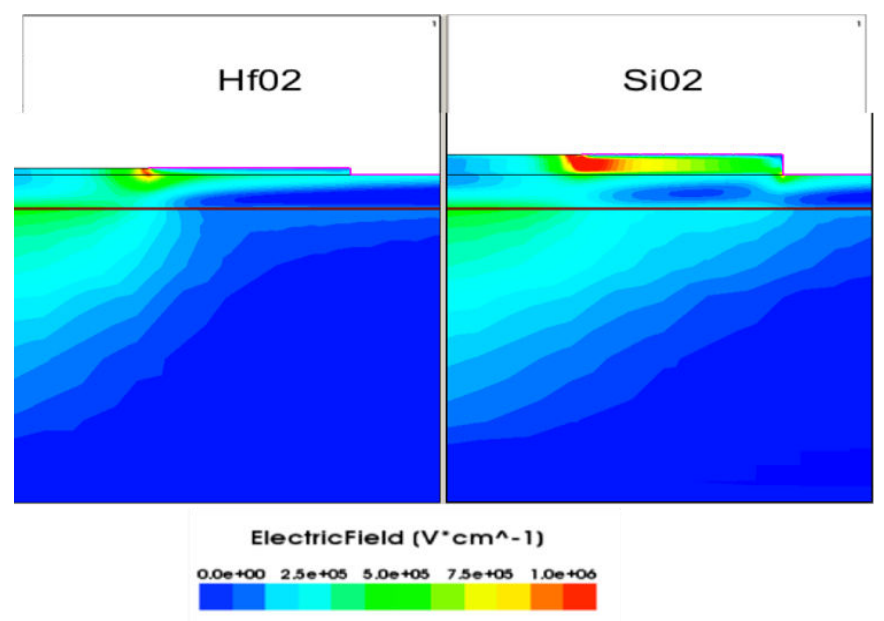

Fig.27. Electric field repartition in $\mathrm{HfO}_{2}$ of $\mathrm{SiO}_{2}$

\section{CONCLUSION}

TLP stress results on Schottky gate contact and Ohmic contact are investigated in this work. Three different $\mathrm{SiC}$ MESFETs are tested against ESD and HBM to test point out for Ohmic contact and the benefits of Zener diode integration to the contrary of Schottky diode. Robustness is improved from $1 \mathrm{~A}$ to $1 \mathrm{C}$ according to JEDEC Classification. 
Two failure mechanisms are identified after stress: only the Zener on drain MESFET is not limited by the first mechanism, corresponding to the intermetallic dielectric $\left(\mathrm{SiO}_{2}\right)$ failure. Its ESD robustness is increased without modifying the electrical dynamic and static characteristics, with no extra cost and is insured by the triggering of a parasitic transistor. However, current filamentation occurs and ultimately limit the device robustness.

Moreover TLP stress results on Schottky gate contact and Ohmic drain contact present a different ESD robustness even if the failure mechanism looks similar.

In contrast with silicon devices case, electrical measurement cannot clearly indicate the device failure because the created hole in the SiC material only marginally impact the device electrical characteristics. Visual analyses are hence presently used when stopping the test just after a failure is observed. Consequently, SiC requires new methods for failure detection that are different of the one used for silicon devices due to its sublimation property.

Lock-in thermography analysis is used in this work and reveals different emission response depending of the failure created and the MESFET studied.

Furthermore, integration of the Zener on Drain MESFET in electronic circuit has also to be experimented and tested in order to validate the ESD robustness improvements.

Finally, TCAD Sentaurus simulation results show that in replacement of $\mathrm{SiO}_{2}, \mathrm{Al}_{2} \mathrm{O}_{3}$ with his high dielectric constant can be a candidate for application requiring high ESD robustness. However a tradeoff has to be found because the realization would be more expensive.

\section{ACKNOWLEDGEMENTS}

Thanks a lot to the LIA Widelab collaboration with the Ampere Laboratory (Lyon, Fr) who has designed the device, the CNM laboratory (Bercelona, Es) who has built them and the LAAS laboratory (Toulouse, Fr) who give the support of LAAS characterization platform and the failure analysis possibility.

\section{REFERENCES}

[1] T. Welsher, "Electrical Overtstress - Many Sources; Any Solutions?", Dangelmayer Associates, ESD Association, Industry Concil on ESD, 2012

[2] C. Raynaud, "Propriétés physiques et électroniques du carbure de silicium (SiC)”, Ed. Techniques Ingénieur, 2007

[3] D. Tournier, Composants de Puissance en Sic. Ed. Techniques Ingénieur, 2007.

[4] P. Denis, P. Dherbécourt, O. Latry, C. Genevois, F. Cuvilly, M. Brault, and M. Kadi, "Robustness of 4H-SiC 1200V Schottky diodes under high electrostatic discharge like human body model stresses: An in-depth failure analysis," Diamond and Related Materials, vol. 44, pp. 62-70, Apr. 2014.

[5] R. Singh, "Reliability and performance limitations in $\mathrm{SiC}$ power devices," in Microelectronics Reliability, vol. 46, no. 5-6, pp. 713-730, May 2006.
[6] J.A. Appels and H. M. J. Vaes,"High voltage thin layer devices (RESURF devices)", in Electron Devices Meeting, 1979, IEDM 1979, IEEE International, 1979, pp 238-241.J.-F.

[7] J.F. Mogniotte, "Conception d'un circuit intégréen $\mathrm{SiC}$ appliqué aux convertisseur de moyenne puissance," Thèse de doctorat, Ed EEA-INSA de Lyon, 07-01-2014.

[8] Agilent, "Precision Impedance Analyzer", 4294A, Datasheet, January 2003.

[9] ESD/JEDEC joint standard for Electrostatic Discharge Sensitivity testing, Human body Model (HBM) - Component level, April 2017

[10] J. León, X. Perpiñà, V. Banu, J. Montserrat, M. Berthou, M. Vellvehi, P. Godignon, and $\mathrm{X}$. Jordà, "Temperature effects on the ruggedness of SiC Schottky diodes under surge current," Microelectronics Reliability, vol. 54, no. 9-10, pp. 2207-2212, Sep. 2014.

[11] O. Breitenstein, W. Warta, M. Langerkamp, "Lock-in thermography: basics and use for evaluating electronic devices and materials" 2nd ed Berlin, heidelberg: Springer-Verlag, 2010

[12] T. Phulpin, D. Trémouilles, K. Isoird, D. Tournier, P. Godignon, and P. Austin, "Failure analysis of ESD-stressed SiC MESFET," Microelectronics Reliability,vol. 55, no. 9, pp. 1542-1548, 2015.

[13] T. Phulpin, D. Tremouilles, K. Isoird, D. Tournier, P. Godignon, and P. Austin, "Analysis of an ESD failure mechanism on a SiC MESFET," Microelectronics Reliability, vol. 54, no. 9, pp. 2217-2221, 2014.

[14] M. Wolborski, Kungliga Tekniska högskolan, and Laboratory of Solid State Electronics, "Characterization of dielectric layers for passivation of $4 \mathrm{H}-\mathrm{SiC}$ devices," Laboratory of Solid State Electronics, Department of Microelectronics and Applied Physics, Royal Institute of Technology (KTH), Stockholm,2006

[15] Y. Hamieh, "Caractérisation et modélisation du transistor JFET en SiC à haute température", thèse de doctorat, INSA Lyon, 152p, 2011

[16] M. Zerarka, "Étude des régimes extrêmes de fonctionnement en environnement radiatif des composants de puissance en vue de leur durcissement pour les applications aéronautiques et spatiales", Université Paul Sabatier - Toulouse III, 2013

[17] B. Courivaud, « Développement et réalisation de nouvelles structures de protection contre les décharges électrostatiques », Université Paul Sabatier - Toulouse III, 2014

[18] L. T. Ngo, "Optimisation et realisation d'une peripherie planar haute tension a poche," Institut National Polytechnique de Grenoble-INPG, Ph.D. thesis, 1997.

\section{AUTHORS}

T. PHULPIN is researcher-teacher at GEEPS and CentraleSupelec (Paris, Fr). He received his PhD. Degree in 2017 for his work on ESD and radiation robustness on $\mathrm{SiC}$ devices. In 2016 he was director, chairman and reviewer of JNRDM conference with 115 participants and a budget of 35k euros. He received an engineer degree in 2013 from ENSEIRB-MATMECA (France) in electrical engineering with a specialization in electronics reliability. He also studied at UFBA (Brazil) and UNIBO (Italy) during exchange semesters. He teaches during 4 years on a large electronic spectrum going from high power to RF and analogic electronic going through physic, and numeric applications.

D. Trémouilles received the M.S. degree in electrical engineering in 2000 and his Ph.D. in microelectronic circuit and microsystem design 
in 2004, both from the Institut National des Sciences Appliquées (INSA) of Toulouse, France. During his Ph.D. degree his research activity focuses on the design optimization, simulation and modeling of ESD protections for BiCMOS technologies. This work was carried out at the Laboratoire d'Analyse et d'Architecture des Systèmes of CNRS (LAAS-CNRS) in collaboration with On Semiconductor Toulouse, France. From October 2004 he was with the reliability researcher group at IMEC (Interuniversity Microelectronics Center), Leuven, Belgium, where he was granted a Marie Curie IntraEuropean fellowship from the European Community. His research interests were on the impact of new technology options and device architecture on ESD robustness, and innovative ESD protection for RF circuits. In April 2007 he joined LAAS to study alternative materials and strategies to protect integrated circuits and systems against ESD and electromagnetic interference in the framework of a Marie Curie European Reintegration Grant. In 2008, he succeeds in the CNRS researcher entrance competition and he is now hired as a full time CNRS researcher since October 2008. Is current research interest focus on ESD high-power and high-speed measurement techniques, dedicated ESD-protection devices and robustness and reliability of new wide band-gap power devices. He is currently the head of the "Power Management System Integration" (ISGE) team at LAAS-CNRS

K. ISOIRD was born at Sète (France) in 1973. Her Ph.D. degree received in 2001, focused on the characterisation of high temperature and high voltage $\mathrm{SiC}$ power device. Since 2003, she is assistant professor at University Paul Sabatier of Toulouse and she has integrated ISGE team (Integration of Systems for Energy Management) within LAAS lab. Her activities research focus on the simulation, design and electrical characterisations of high voltage and high temperature power devices both in silicon, or wide band gap material. Indeed in recent years, she has been involved in several projects for the design and realisation of devices dedicated to high temperature applications, such as Thyristor, GaN HEMT or diamond Schottky diodes. She is co-authors of 20 publications in scientific journals and 15 in international conferences. She is member expert to OMNT (Observatory for Micro and Nano Technology), on the topic Wide band gap Materials, since 2013.

P. AUSTIN recieved the Ph.D. degree in Electronic from the Paul Sabtier University of Toulouse, France, in 1993. He is currently Profesor and he work with the ISGE team of the LAAS-CNRS. His current research interests are in the modeling and conception of power semiconductor structures.

X. PERPINYA (Almenar 1976). He receive the B.S. degree in physics, the M. Phil. degree in electronic engineering, and the Ph.D. degree from the Universitat Autònoma de Barcelona, Barcelona, Spain, in 1999, 2002, and 2005, respectively. In 1999, he joined the Institut de Microelectrònica de Barcelona-Centro Nacional de Microelectrónica (IMB-CNM) of Spanish Research Council, Bellaterra, Spain. There, he began his research activity with the Power Devices and Systems Group until 2005. From 2005 to 2007, he was with Alstom Transport. He is currently a Ramon y Cajal Fellow at IMB-CNM. He has authored or co-authored more than 130 research papers published in international conference proceedings and journals, and has edited two books and holds several patents on railway hot topics. He belongs to THERMINIC and EUROSIME conference scientific committees. His research interests include electrothermal characterization, reliability and layout robustness improvement in power devices, integrated circuits, and packaging for power applications.

M. VELLVEHI (Mataró 1968) received the B.S degree in Physics from the UniversitatAutònoma de Barcelona in 1992 and the Ph.D degree in Electrical Engineering at the same university in 1997 with his dissertation addressing the analysis of the thermal behaviour of Lateral Insulated Gate Bipolar Transistors In 1993 he joined the Power Devices \& Systems Group of the Institut de Microelectrònica de Barcelona del Centre Nacional de Microelectrònica (IMBCNM,CSIC) in Cerdanyola del Vallès (Spain). In 2007 he gained a permanent position at CNM-CSIC. From 1993 to 1998, his research activities include technology, modelling, and numerical simulation of MOS-controlled power semiconductor devices. Since 1999, his main research activity deals with electro-thermal characterization and modellisation of power semiconductor devices and circuits. He has authored and co-authored more than 100 research papers in journal and conferences. 